Acta Poetica 25-1

PRIMAVERA

2004

\title{
La visión trágica de la vida en la obra de Luigi Pirandello
}

\begin{abstract}
Annunziata Rossi
Pirandello y la "sicilianidad". Tema central de la obra narrativa y teatral de Pirandello: la problemática relación del individuo con la sociedad. Éxito del teatro pirandelliano en la primera posguerra europea. Trilogía narrativa sobre el tema de la identidad: El difunto Matías Pascal, Serafino Gubbio camarógrafo, Uno, ninguno y cien mil. El difunto Matías Pascal y la influencia del pensador francés Blaise Pascal. El heliocentrismo copernicano y el inicio de la crisis del individuo moderno. La psicología de Pirandello: Los diálogos entre el Gran Yo y el Pequeño Yo. La relación vida-forma. La vida como juego de máscaras. Humorismo pirandelliano. Pirandello dramaturgo.
\end{abstract}

Pirandello and "Sicilianity". The problematic relation of the individual with society: main subject of Pirandello's narrative and dramatic works. Success of Pirandello's theatre during the first European post-war period. Narrative trilogy concerning the topic of identity: The late Mattia Pascal; Shoot! (si gira) the Notebooks of Serafino Gubbio, Cinematograph Operator; One, No one and One Hundred Thousand. The late Mattia Pascal and the influence of the French Philosopher Blaise Pascal. Copernicus' heliocentric system and the beginnings of the crisis of modern individual. Pirandello's Psychology. Dialogues between the Great Self and the Small Self. Relation between life and form. Life as a mask game. Humor in Pirandello. Piradello as a playwright. 


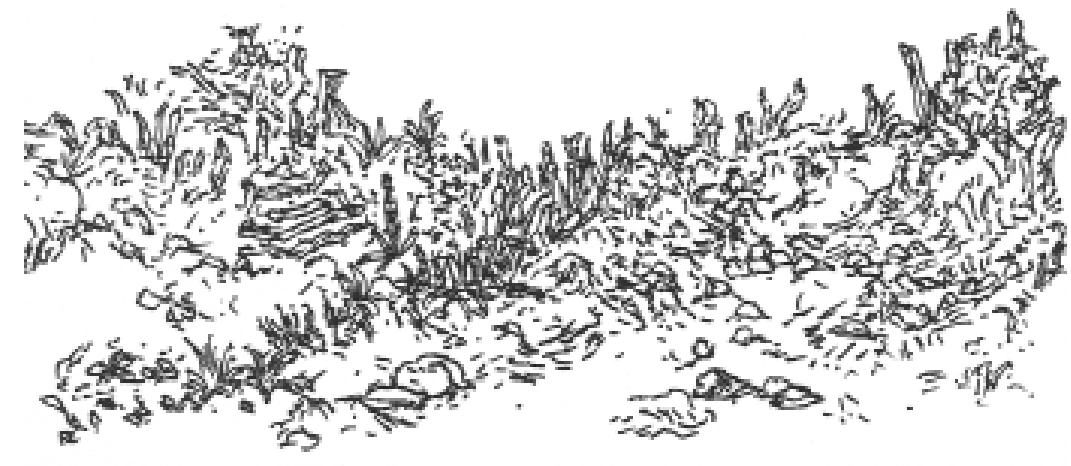


Acta Poetica 25-1

PRIMAVERA

2004

\section{Annunziata Rossi}

\section{La visión trágica de la vida en la obra de Luigi Pirandello}

Para Federico Campbell

Cuando en una entrevista se le preguntó a Leonardo Sciascia quién era, contestó: "uno, ninguno y cien mil", el título de una célebre novela de Pirandello. Una respuesta, pues, que podría haber dado cualquiera. Algo más une a Sciascia y Pirandello, no obstante las generaciones que los separan, y es un modo de ser, la "insularidad", la sicilianidad. Como dice Sciascia, una "insularidad vencida", a diferencia de la insularidad victoriosa de Inglaterra. No obstante, Sicilia marca profundamente a todos sus escritores y artistas — de Giovanni Verga y Pirandello, a Tomasi di Lampedusa, Brancati, Sciascia, etc.- , ligados a ella por una relación de amor-odio, de insatisfacción por su realidad histórica, fruto de las diversas estratificaciones culturales que se han alternado y condensado en la isla: la griega, la latina, la árabe, la normanda, la española, hasta esa unidad italiana hacia la cual han manifestado su rechazo los movimientos separatistas del siglo XIX y de la segunda posguerra mundial del siglo xx. Antonio Gramsci, hablando de Sicilia, observa que cincuenta años de vida unitaria habían sido en gran parte dedicados por los políticos a crear la apariencia de una uniformidad italiana inexistente: los pequeños estados que 
conformaban a Italia antes de su unidad en el siglo xIx hubieran tenido que desaparecer en la nación, los dialectos en la lengua literaria. Sicilia, sigue diciendo Gramsci, es la región que más activamente ha resistido a esa manipulación de la historia y de la libertad, y ha demostrado que vive una vida con carácter nacional propio más que regional, manteniendo una independencia espiritual manifiesta de manera más espontánea y con mayor fuerza en el teatro. Sin embargo, el inmovilismo político siciliano, su arcaica y sofocante estructura social (estamos hablando de los tiempos de Pirandello), su atraso económico y — last but not least - la mafia siempre omnipotente, provocan el fenómeno impresionante de la deserción al Norte de sus trabajadores, paralela al abandono de sus intelectuales que se van al "continente", desde Nápoles y Roma hasta el norte. Hay que añadir que Italia recibió y sigue recibiendo de Sicilia y del sur de la península la mayoría de sus intelectuales y entre ellos a Luigi Pirandello, que "emigró" a Roma, en donde, además de dedicarse a su obra, ejerció una larga actividad docente.

Sicilia es el punto de partida de las creaciones de Pirandello, cuyas tramas, estrafalarias y paradójicas, han sido a menudo criticadas como inverosímiles. Nacen, sin embargo, de situaciones reales. Sus personajes son, en su mayoría, sicilianos. Pirandello no los elige, los toma al azar, como le salen al encuentro, como un "pescador con su red". Son, por lo general, provincianos de la pequeña burguesía, casi siempre vestidos de negro como para expresar un eterno luto; campeones, como dice Leonardo Sciascia, de aquella "onomástica siciliana" - Alcozèr, Bobbio, etc. - que se puede encontrar en el directorio telefónico de la provincia de Agrigento, donde nació Pirandello, precisamente en la villa paterna de Caos, nombre casi emblemático de su obra futura. El escritor los encuentra en el momento en que la explosión de un hecho imprevisto, casi siempre grotesco —en el sentido que le da Jan Kott, lo 
que un día fue trágico hoy es grotesco-, despierta la conciencia de sus protagonistas y rompe de manera determinante la tranquilidad sólo aparente de su modesta, rutinaria existencia. Nace así el conflicto que los enfrenta a la inquietante pregunta: ¿quién soy?, pregunta a la cual es imposible responder, ya que el hombre está hecho de múltiples individuos: uno, ninguno y cien mil.

A partir de esa realidad regional, Pirandello llega a una realidad más universal, ya que al dirigir su atención al individuo en su problemática relación con la sociedad, logra registrar la crisis del individuo como unidad que trasciende los límites de Sicilia, mucho antes de que la explosión de la Primera Guerra Mundial la revelara a la conciencia europea. En una reseña de El Placer de la honestidad, Antonio Gramsci, que de 1916 a 1920 fue crítico teatral del "Avanti!" de Milán, afirmaba que las comedias pirandellianas eran bombas de mano que explotaban en el cerebro de los espectadores produciendo derrumbes de banalidades, ruinas de sentimientos y de pensamiento, imágenes de vida que se salen de los esquemas acostumbrados de la tradición.

La narrativa pirandelliana pasó casi inadvertida hasta la primera posguerra del siglo xx, cuando el revuelo que causó el escritor con su teatro y la irrupción de las corrientes irracionales filosóficas orientaron el interés hacia él. Sciascia explica este hecho observando que Pirandello presintió una realidad de la que las sociedades europeas tomaron conciencia sólo después de la Primera Guerra Mundial, que hizo tábula rasa de la Europa de preguerra: "En una Europa tranquila, cómoda, dice Sciascia, apenas sacudida por escalofríos sociales, toda emocionada por descubrimientos arqueológicos y jubileos regios, Pirandello entreve la feroz y grotesca máscara de un mundo convulsionado, enloquecido". El éxito le llega "cuando los hombres que regresan de la guerra advierten con terror el disolverse de su identidad, la trágica desintegración de su yo, el loco juego de espejos alrededor de su individualidad mutilada". 
De la vasta producción narrativa de Pirandello, me detendré en tres novelas de innegable valor literario y cultural que, en mi opinión, constituyen una trilogía alrededor del tema de la identidad: Il fu Mattia Pascal (El difunto Matías Pascal), I quaderni di Serafino Gubbio operatore (Los cuadernos de Serafino Gubbio camarógrafo), Uno, nessuno e centomila (Uno, ninguno y cien mil), así como en uno que otro relato. Con El difunto Matías Pascal, de 1904, empieza la crisis del personaje, que es el tema obsesivo de la obra narrativa y teatral del escritor de Agrigento. Pirandello enfrenta con medio siglo de anticipación el problema de la identidad que, no por haberse puesto de moda, deja de ser un problema angustioso. Se ha hablado de la crisis de identidad como del "nuevo mal del siglo". "Cuando se hunden hábitos seculares, cuando desaparecen modos de vida, cuando se evaporan las viejas solidaridades, dice Lévi-Strauss en 1977, es fácil, por cierto, que se produzca una crisis de identidad". Y es obvio que el problema de la identidad está ligado estrictamente con el de la alteridad. No hay una sin la otra, como ocurre en Pirandello.

Pascal no es un patronímico siciliano. Leonardo Sciascia revela, y creo que ha sido el único en hacerlo, que Matías Pascal repite, diluyéndolo a lo largo de su narración, un pensamiento de Blaise Pascal a quien Pirandello admiraba. Cito al pensador francés: "Yo no sé por qué he venido al mundo, ni quién soy. Y si me pongo a reflexionar regreso confundido por una ignorancia cada vez más pavorosa. No sé qué son mi cuerpo, mis sentidos, mi alma; esta parte de mí que piensa lo que estoy escribiendo y que medita sobre todo y sobre sí misma nunca puede conocerse. En balde intento medir estos inmensos espacios del universo que me rodea...". ¿Se trata de una reminiscencia involuntaria de la lectura de Pascal, o bien de una referencia precisa al pensador francés, en un momento en el que Pirandello llega a acariciar la idea del suicidio o de la huida? A la cita de Sciascia se pueden añadir otras de El difunto 
Matías Pascal que prueban cómo la referencia a Blaise Pascal es intencional, y de hecho Pirandello lo cita de manera explícita en uno de sus relatos, "Sopra e sotto" ("Arriba y abajo"), donde la visión trágica pascaliana es el núcleo de la violenta discusión entre los dos protagonistas.

Al inicio de su narración, Matías Pascal impreca de vez en cuando "¡Maldito sea Copérnico!”, y a don Eligio, que le pregunta qué tenía que ver Copérnico, le contesta: "Sí que tiene que ver. Copérnico ha arruinado irremediablemente a la humanidad. Antes de Copérnico la gente no sabía que la tierra giraba, y era como si no girara. Nosotros poco a poco nos hemos acostumbrado a la nueva concepción de nuestra infinita pequeñez, y a considerarnos menos que nada en el universo, con todos nuestros bellos descubrimientos e invenciones...", y Matías concluye con amargo humorismo que la humanidad ha sido reducida a unos millares de bichos quemados por el sol.

Está claro que Pirandello ve el inicio del proceso de desintegración del individuo en el heliocentrismo copernicano, en la transición del "mundo cerrado al universo infinito" que destronó al ser humano de su posición privilegiada, provocando una crisis de identidad que se manifiesta precisamente a partir del Barroco, cuando la humanidad empieza a percibir con espanto la inconstancia de todas las cosas, su oscilación entre el ser y la nada. Y fue precisamente Pascal el primero en experimentar frente al descubrimiento copernicano la crisis del cambio; frente al espacio infinito Pascal sintió vértigo, pavor, soledad, sentimientos que están en la base de su concepción pesimista del mundo. Nadie como J. L. Borges, en su "Esfera de Pascal", ha sabido revivir el terrible impacto que el universo infinito provocó en el pensador francés. "La naturaleza, dice Pascal, es una esfera infinita, cuyo centro está en todas las partes y la circunferencia en ninguna". Pero, observa Borges, Pascal en el borrador había cancelado un adjetivo que es testigo del terror cósmico que lo había sacudido: había es- 
crito, en lugar de sphère infinie (esfera infinita), sphère effroyable (esfera espantosa). El ser humano frente al espacio vacío tiene miedo de perderse, y su vértigo en el campo del arte se vuelve metáfora de la pérdida de identidad. Hay que observar que cuando Matías repite "¡Maldito sea Copérnico!” habían pasado otras dos revoluciones, la darwiniana y la freudiana, que habían empobrecido todavía más la imagen del ser humano, reduciéndolo a un átomo infinitesimal en un mundo sin Dios.

Con El difunto Matías Pascal inicia, como ya se dijo, la desintegración individual de los personajes pirandellianos, desintegración que el escritor siciliano continuará de manera obsesiva, martillante, en las dos novelas sucesivas ya citadas que constituyen, en mi opinión, una trilogía. El protagonista Matías, que narra su "caso" en primera persona, es uno de los tantos "muertos-vivos" que encuentran su alter ego en la vida real (a menudo los encontramos en las crónicas de los periódicos, la mayoría de ellos desaparecidos para siempre). El Matías adolescente lleva una vida descabellada, es uno de los "muchachos de vida" que la provincia produce, que desahogan su energía vital en actos gratuitos, aparentemente inocuos pero que pueden determinar el curso de una vida, como en el caso de Matías, que cae en la trampa de un matrimonio forzado y opresivo. Con un dinero caído del cielo se aleja de su pueblo por un breve lapso y llega a Montecarlo donde gana una fortuna. Cuando está por regresar a su casa lee en un periódico que se había encontrado en el río de su pueblo el cadáver de Matías Pascal. Decide desaparecer definitivamente.

Libre de la identidad de Matías Pascal, dueño virtual de una plena disponibilidad — palabra clave de la narrativa del siglo $\mathrm{xx}$-, está en condición de construirse una nueva existencia más acorde con su ser íntimo. Se le ofrece la posibilidad de saber no sólo lo que no es y no quiere, sino lo que es y lo que quiere ser. Pero, después de una veleidosa intención de cam- 
bio: "me hubiera gustado, dice, que no sólo exteriormente, sino también en lo íntimo no quedara ningún rasgo de mi viejo yo", es incapaz de abrirse a la metamorfosis que se había propuesto, y permanece esclavo de las presiones de la identidad externa. En fin, una vez que ha logrado escapar, de pura casualidad, de la condición insatisfactoria que su estado civil le había impuesto, concluye que sin estado civil, sin los documentos que lo legalicen en forma manifiesta frente a la sociedad, no puede vivir. El hecho es que Matías es un burgués de buena fe, que cree en el mito de los valores de la respetabilidad, de la decencia, del honor, de la legalidad, y en el respeto de esos valores, quiere construirse una vida de auténticos afectos familiares. Detesta la mentira a la que se ve obligado bajo el falso nombre de Adriano Meis. Entonces, finge el suicidio de Meis para poder reencarnar en Matías Pascal. Pero, al tener que renunciar a sus derechos sobre su esposa (que encuentra casada y con un niño), se convierte en nadie: el "difunto Matías Pascal". Así, el viaje que hubiera podido ser de iniciación, de encuentro con su verdadero ser, concluye en un paréntesis que lo deja prácticamente fuera del estado civil; armado, esto sí, de un humorismo que le hace aceptar su fracaso.

Otro siciliano de carne y hueso, Ettore Majorana, ya había demostrado que se puede desaparecer sin dejar huellas. En efecto, el más grande físico italiano, preocupado por el camino peligroso que iba tomando la física, desapareció sin dejar rastro, no obstante las búsquedas del gobierno italiano. Majorana había sido gran lector de Shakespeare y de Pirandello, sobre todo $E l$ difunto Matías Pascal. La hipótesis de Sciascia, tras una estupenda investigación sobre el físico italiano, de que la novela le había sugerido la idea de desaparecer, es más que probable. Cuando salió la novela, Benedetto Croce, que pocas simpatías tenía para la narrativa contemporánea, comentó con ironía que se trataba de un drama de registro civil. Dicho sin ironía, esto es El difunto Matías Pascal, un drama de registro civil. 
Después de esta obra vienen Los cuadernos de Serafino Gubbio camarógrafo, de 1915, que son un paso obligado para llegar a las conclusiones de Uno, ninguno y cien mil. Si Matías Pascal resultó incapaz de ver al "altro da sé" ("otro que sí mismo"), Serafino Gubbio —él también narrador en primera persona - declara desde el inicio que "hay algo más allá en todas las cosas", y lo busca. Este algo más allá no es, como podría suponerse, algo metafísico, externo al individuo, sino más bien el "otro" que está adentro de uno, relegado y condenado al silencio. O mejor dicho, según Serafino, "el ser íntimo, a menudo destinado a ocultársenos por toda la vida". Una de las protagonistas de la novela, la actriz Naria Nestoroff - que recuerda a las heroínas obsesas de Dostoiewski- queda pasmada, estremecida ante su propia imagen en la pantalla, ve a una que es ella, pero que no conoce; quisiera no reconocerse en ella, pero por lo menos conocerla. Es evidente que percibe en esa imagen el lado tenebroso, oscuro, de su ser.

Ese "algo más allá" inexplicable puede ayudarnos a entender otro texto de Pirandello, los Dialoghi tra il Gran Me e il Piccolo Me (Diálogos entre el Gran Yo y el Pequeño Yo), donde el "Pequeño Yo", esa conciencia normal, esas ideas acomodadas, ese sentimiento burgués de la vida, son una simple astucia que nos ayuda a vivir, mientras que el "Gran Yo" es el otro al que el hombre no puede enfrentar sin arriesgarse a la muerte, al suicidio o a la locura. Así, los personajes pirandellianos, divididos entre el impulso hacia la trasformación y la incapacidad o la imposibilidad de lograrla, viven un desdoblamiento que los hace infelices. En fin, el narrador Serafino Gubbio indica, sin formularlo claramente, el desequilibrio entre consciente e inconsciente. Ese "dios terrible", el Gran Yo —diabolus absconditus, como lo llama irónicamente Giacomo Debenedetti, uno de los críticos más inteligentes del escritor siciliano-, irrumpe en los dominios visibles del yo, trastornando la fisonomía de los protagonistas, deformándola en sentido expresionista. 
De hecho casi todos los personajes pirandellianos son caricaturescos, llenos de tics, desagradables, máscaras que ocultan una conciencia infeliz. Su deformación exterior es la manifestación física de un desequilibrio interno, de una tara moral, de una sorda infelicidad que se manifiesta en la fealdad de los rostros (Matías Pascal es estrábico, no tiene mentón y se oculta tras la barba). La metamorfosis negada - las "tantas vidas muertas" que el ser humano alberga - se venga a través de la fealdad de los rostros, de la misma manera que en Elías Canetti la metamorfosis reprimida, atrofiada, sobrevive en la mímica, en la gesticulación.

En Los cuadernos de Serafino Gubbio camarógrafo el problema de la identidad-alteridad se entrelaza también con la crítica despiadada a la máquina, ese "monstruo" que devora el alma del ser humano y mecaniza la vida: "nueva divinidad" que de instrumento de liberación se ha convertido en instrumento de esclavitud y con el tiempo sustituirá a la humanidad. Doble enajenación, pues, para el ser humano: la máscara y la máquina. Siempre por boca de Gubbio - técnico que termina reduciéndose a "una mano que maneja una manivela"-, Pirandello amplía su crítica al cine, que aborrece; a sus mecanismos, subrayando el extrañamiento del actor que está obligado a actuar ante la maquinaria, al contrario del actor de teatro que actúa frente a su público. Veinte años después, Walter Benjamin en "La obra de arte en la época de su reproducibilidad técnica" (1936) retoma la crítica de Pirandello y la hace suya, citando algunos párrafos de la novela y ahondando en ellos. Cita a Pirandello cuando dice que el actor de cine se siente como en el exilio; exiliado no sólo de la escena, sino de su propia persona. La actuación del actor de cine, continúa Benjamin, apoyando al escritor de Agrigento, "no es unitaria sino que se compone de muchas ejecuciones" ya que "las necesidades de la maquinaria desmenuzan la actuación del artista en una serie de episodios montables", provocando el extra- 
ñamiento que es tal y como lo describe Pirandello: de la misma índole que el que siente el hombre ante su aparición en el espejo. El espejo, otra obsesión pirandelliana...

Uno, ninguno y cien mil (publicada en 1925, pero iniciada diez años antes) es, como dice su autor, la novela que "llega a las conclusiones más extremas, a las consecuencias más lejanas". La continuó años más tarde, sometiéndola a cambios que le causaron una enorme fatiga. Mientras tanto, publicaba cuentos y llevaba a la escena varios dramas, entre ellos Seis personajes en busca de autor y Enrique IV. El autor lamentó siempre el haberla publicado "a destiempo", porque en ella "está la síntesis completa de lo que hice y de lo que haré. Hubiera tenido que ser el proemio de mi obra teatral y será, al contrario, su epílogo".

En Uno, ninguno y cien mil, Pirandello lleva a su conclusión aquel proceso de desintegración individual que había empezado en El difunto Matías Pascal. El protagonista, Vitangelo Moscarda, se niega definitivamente al yo que él es para los otros. Gianfranco Venè indica, si se quiere esquemáticamente pero con gran claridad, las etapas por las que pasa la maduración de los protagonistas del escritor. La primera es la pasiva, cuando el ciudadano acepta las relaciones legales con la sociedad y tiene la ilusión de que sean justas. La segunda se inicia con la toma de conciencia del yo no expresado, y con la constatación de que la sola relación posible con los demás está mediada por la máscara falsa y asfixiante que cada uno está obligado a llevar para significar algo a los ojos de la comunidad; es cuando el protagonista toma conciencia de la ilusión de que ha sido cómplice. La tercera sería cuando su situación le parece insoportable; es decir: el momento de la rebelión. Yo añadiría una última fase, en la que, agotada la lucha estéril en contra de las estructuras sociales, el personaje se encuentra frente a dos alternativas: o la aceptación y la conformidad, como en el caso de Matías, o la huida de la vida, como en el caso de Vitangelo. 
La rebeldía individual, sostiene Pirandello, es ilusoria pero necesaria, muy necesaria, en cuanto lleva al individuo a tomar "conciencia" - palabra muy recurrente en la obra pirandelliana- de su inutilidad, porque la conciencia individual no coincide ni puede coincidir con la conciencia social. Esta escisión entre individuo y sociedad no sólo es inevitable sino grave, ya que el individuo, por su misma naturaleza "está abierto a los demás”, necesitado de los demás. Sin embargo, la relación entre el yo y los otros nunca podrá ser auténtica porque está mediada por la "máscara" que es falsa. Esta condición deriva de la sociedad que, en cuanto tal, es represiva y el individuo, auto-represivo. Pirandello llega, por tanto, a la misma conclusión a la que llega Freud a través de sus estudios científicos. La represión es la palabra clave del sistema freudiano que, como se sabe, la considera como la esencia de la sociedad, así como la esencia del individuo es la auto-represión. Dicho sistema hace hincapié en el "inconsciente dinámicamente reprimido", y en el consciente como órgano de adaptación al ambiente y a la cultura. Pirandello, se sabe, leía muchos libros de psicología y releía a menudo Les altérations de la personnalité de Alfred Binnet, pero no conocía a Freud. Se habla mucho de las sugestiones freudianas en la obra de Pirandello, atribuyéndolas al hecho de que el psicoanálisis en aquel momento estaba ya en el aire (aunque no en Italia). Más convincente me parece el mismo Freud cuando dice que lo que la ciencia descubre está presagiado y anunciado mucho antes por la literatura, por el arte; el inconsciente está presente en la literatura aunque no formulado en términos científicos. Me remito a Hermann Hesse, que lo confirma cuando dice que "hay más verdad directamente legible en una obra de arte con respecto a las que son las grandes corrientes del alma colectiva, que en muchas otras producciones; en verdad, el inconsciente siempre aflora en la obra de arte". Y el inconsciente de los personajes pirandellianos, censurado y reprimido, hierve, protes- 
ta, reclama, presiona para salir a flote, y se manifiesta bajo la forma de perturbaciones y delirio, de una angustia perenne, la angustia del sujeto destrozado por su subsuelo.

La visión pirandelliana se configura como la ineludible separación entre la "criatura" sacrificada y la "máscara" con la que se presenta ante los demás y que es lo único que éstos ven de ella. A su vez, la criatura sólo ve las máscaras, ya que los demás son también máscaras. Esta separación se traduce en la incomunicabilidad y en la soledad; de aquí el significativo título que Pirandello da a toda su obra teatral: Máscaras desnudas. La vida es un juego de máscaras, un juego de representaciones en el que los seres humanos son, a sabiendas o no, actores que desempeñan un papel que nada o poco tiene que ver con la verdad de su yo profundo que, además, no es conocible. La única verdad es la del arte, superior a la vida, que es pura ilusión. Sólo las obras de arte, dice Pirandello, tienen una consistencia eterna. La existencia humana es efímera: "Todo lo que vive, por el mismo hecho de estar vivo, tiene una forma y por eso mismo muere; excepto la obra de arte que, en cuanto forma inmutable, vive para siempre". Es el caso de referir una anécdota real y humorística que confirma la posición del escritor. Un senador de carne y hueso tiene por casualidad el nombre del personaje antipático de una comedia de Pirandello. Una personalidad del mundo de la política pide al escritor que, para evitar malentendidos, cambie el nombre de su personaje. Pirandello contesta con humor: “¿Por qué? Mi personaje es una criatura de arte, existe; el de ustedes en la vida cuenta cero, no existe. ¿Cómo quieren que un personaje real ceda el paso a uno inexistente? Si ese nombre fastidia a su senador, que lo cambie él".

Toda la obra de Pirandello está mediada por el humorismo que subraya de manera paradójica las contradicciones y los absurdos de la vida, los aspectos dolorosos de la felicidad y los lados risibles del dolor. Hilaris in tristia et tristis in hilaritate, ha- 
bía dicho de sí mismo Giordano Bruno, a quien Pirandello cita en su largo ensayo sobre el humorismo. El humorismo de Pirandello va más allá, nace del "sentimiento de lo contrario", de la desproporción entre una situación real y objetiva y una condición individual opuesta, una desproporción entre la vida real y el ideal: lo que se es y lo que se cree ser. En este sentido Pirandello puede decir que Copérnico ha sido el primer gran humorista moderno.

A lo largo de Uno, ninguno y cien mil, Pirandello retoma los temas anteriores, enriqueciéndolos: la angustia del relativismo — no existe una realidad fuera de nosotros- de la identidad imposible, del juego entre el ser y el parecer, entre la criatura y la máscara, entre la realidad y la ficción, que se imbrican de tal manera que es difícil discernir los límites que las separan; de allí la imposibilidad de conocer la realidad tras las apariencias. La múltiple personalidad del ser humano, que supondría el libre desplegarse de fuerzas vitales en una continua metamorfosis —en un sentido cercano al que le dará Elías Canetti-, se ve impedida por el trágico conflicto inmanente entre la Vida que se mueve y cambia y la Forma determinada por las normas, las leyes, las costumbres de una sociedad que todo lo fija y lo inmoviliza en una identidad fija, antivital. Y este verse forzado a una identidad fija lleva al ser humano a un desdoblamiento - tanto en el nivel de su intimidad como en el nivel de su relación social- que produce neurosis, esquizofrenia, locura, e incluso puede conducir al suicidio. El escritor siciliano se debate entre dos alternativas que se excluyen. Su problema es todavía el del romanticismo: contraste entre la Vida - movimiento vital, cambio, contenido- y la Forma - la ley estática - que reduce al género humano a la esclavitud aplastante. Los románticos no lograron llevar a un equilibrio estos dos polos, ni desde el punto de vista práctico ni metafísico. En su última novela, Pirandello resuelve el contraste disgregándolo desde la raíz, en la negación. 
La formulación, debida a Adriano Tilgher, de la oposición vida-forma como núcleo de la obra pirandelliana ha dado motivo en Italia a muchas especulaciones filosóficas que llevaron a hablar de "pirandellismo". Son especulaciones, dice Leonardo Sciascia, que descuidan los valores poéticos y literarios de una obra tan variada y compleja: "un mundo de poesía fue consumido y calcinado hasta el punto de convertirlo en filosóficas cenizas". Hay que ver qué significa esa oposición en la obra del escritor y no en sus declaraciones hechas bajo la influencia de Tilgher. Hablar de oposición entre vida y forma es una contradicción, porque la antinomia está entre la misma vida que debería ser un proceso de metamorfosis, "un incesante fluir de forma en forma en el que cada forma vive de la muerte de otra". Sin embargo, no es así. La sociedad represiva, el mundo moderno dedicado exclusivamente a la producción, a lo útil y a la especialización, que descuida lo múltiple y lo auténtico, paralizan ese fluir y lo condenan a una forma fija. Por eso, los seres humanos sufren silenciosos, solos. Encerrados en sí mismos, viven, trabajan enajenados con metas que no les pertenecen y, al final de su vida, se dan cuenta con pánico de que nunca han estado vivos. Bajo el yugo de la máscara inmutable de la que no han sabido desvincularse, sienten con horror no haber tenido nunca una verdadera vida; han vivido su vida "en el ojo siempre abierto e implacable de los otros" (Sciascia). Ninguno de ellos se reconoce en esa máscara, y todos advierten con espasmo el hervor de una vida distinta, que no es suya, pero hubiera podido serlo... Todos, dice un personaje pirandelliano, "desperdiciamos y ahogamos cada día el florecer de quién sabe cuantos gérmenes, cuantas posibilidades que hay en nosotros (...), obligados como estamos a continuas mentiras, a hipocresías".

De la forma que inexorablemente los inmoviliza, los personajes de Pirandello pueden salvarse en la locura o en la ficción de la locura (Enrique IV), o en el suicidio (Uno y dos, Vestir a 
los desnudos), o en momentos de evasión, como el protagonista de La carriola, severo jurista que saborea todos los días, a escondidas y temblando, "la voluptuosidad de una divina locura consciente, que por un momento (lo) libera y venga de todo". La zancadilla que el protagonista asesta, en un ritual que se repite todos los días, siempre igual y en la misma hora, a su vieja perra, que lo mira con ojos "aterrados", es la manifestación neurótica de la angustia. En este caso, como en otros, es la razón la que se encarga de ir más allá de sus propios límites, en una zona de locura, como tentativa terapéutica, exorcismo necesario para regresar del efímero goce a la insoportable realidad. Patología de la vida cotidiana, pero gesto liberatorio para no caer en la locura permanente.

Los personajes pirandellianos se debaten permanentemente entre sentimientos que no saben conciliar: ávidos de vida pero "desnudos de energía", nati morti (nacidos muertos, como diría Eugenio Montale). ¡Evadir! ¡Trasformarse! ¡Volverse otro!, es un anhelo vuelto imposible no sólo por la forma, la persona-máscara que, como se dijo, traga los rostros del ser humano, sino por el sentimiento contrario: ¡Ay del que se mira! ¡Conocerse es morir! Esa máscara que lo fija a uno en un papel inmutable, aniquilador de su vitalidad, no sólo es determinada por las imposiciones sociales, el filisteísmo burgués, sino por el mismo ser que tiende a creerse y hacerse creer distinto de lo que es, a conformarse al modelo social y cultural de la época en que vive. Viviendo en sociedad, dice Serafino Gubbio, nos construimos. Pirandello analiza estos rasgos psicológicos sin trasladarlos, como hará Canetti o Sciascia, al Poder como instrumento de la represión de la personalidad individual.

El drama del protagonista de Uno, ninguno y cien mil, Vitangelo Moscarda - ivaya nombre!- empieza por un hecho banal: el descubrimiento, frente al espejo, de que su nariz pende hacia la derecha, un hecho del que nunca se había dado 
cuenta y que le revela su esposa. Ese hecho tan irrelevante y grotesco hace estallar el drama existencial de Vitangelo, lo pone frente a la pregunta: ¿Quién soy yo para mí y para los demás? Se da cuenta de que él no es uno, sino tantos como son los que lo conocen, según la imagen que cada uno se hace de él. Empieza, a diferencia de Matías Pascal, la desesperada búsqueda de su identidad. Pasa horas frente al espejo observándose para encontrarse, pero sólo se pierde.

El tema del espejo está presente en otra novela contemporánea a la de Pirandello, Niebla de Miguel de Unamuno. Su protagonista, Augusto Pérez, dice: "Mirándome al espejo, a solas, acabo por dudar de mi existencia e imaginarme, viéndome como otro, que soy un sueño, un ente de ficción...". No se puede hablar de influencias entre los dos escritores, ya que ninguno de los dos conoció la obra del otro. El punto de encuentro podría buscarse, según sugiere Sciascia, en la "hispanidad" de Sicilia, vía Don Quijote (a quien Pirandello dedica páginas de su ensayo sobre el humorismo). Sciascia acude a un ensayo de Américo Castro, "Cervantes y Pirandello", para subrayar la afinidad entre los dos escritores, que derivaría de Cervantes: la interferencia entre lo real y lo fantástico, la doble identidad de sus personajes, etc. Sin embargo, hay que buscar esa afinidad también en las inquietudes del tiempo, de las que Pirandello y Unamuno fueron geniales anticipadores.

El espejo - símbolo sapiencial en muchos contextos históricos y culturales - es una presencia obsesiva en Pirandello. La contemplación de su propia imagen en el espejo no es sólo un acto de vanidad, es una operación intelectual de autoconocimiento, de confirmación de la identidad. Los personajes pirandellianos buscan al otro inaccesible que en ellos está oculto y que generalmente les inspira miedo (hemos visto con qué terror Varia Nestoroff mira su imagen en la pantalla). En uno de sus estupendos y alucinantes cuentos, "La giornata" (La jornada) el protagonista se observa en el espejo y de inme- 
diato tiene la impresión de hundirse en un abismo sin límites. Experimenta un sentimiento de extrañeza: la imagen reflejada es un simulacro, una proyección falaz que sólo revela su corporeidad y su finitud, por ende la muerte.

En el escritor siciliano el espejo conserva la misma polaridad que en la antigua Grecia: en los misterios órficos y en la tragedia, donde el conocimiento puede llevar a la muerte. Porque si por un lado el frontón del templo de Delfos impone el "conócete a ti mismo", por otro lado el adivino Tiresias lo contradice cuando anuncia el destino de Narciso: vivirá largos años a condición de que no se conozca. Si el sentimiento de vanidad mueve inicialmente a Narciso, lo que lo lleva a la muerte es la revelación en el agua de su propio rostro y de lo que oculta: su precariedad, su fugacidad, su finitud. Dionisio fue destrozado por los titanes mientras se miraba al espejo. La voluntad de saber lleva a Edipo a la oscuridad del vientre materno y a la ceguera. Lo mismo es para Pirandello. Conocerse es perderse, es morir: “ ¡Hay del que se mira!, ¡conocerse es morir!".

En el vano intento de conocerse y liberar su yo de las superestructuras adquiridas, de "demoler aquel yo que era para los demás", el protagonista de Uno, ninguno y cien mil se crea fama de loco y, rechazado por todos, perseguido legalmente por su esposa, termina en un hospicio donde, sin embargo, hallará la paz en la soledad y en la cercanía de la naturaleza. Concluye que si el yo es un yo sólo para los demás, mejor no ser. El ser humano sólo puede lograr su autenticidad fuera de las relaciones humanas y en el contacto con la naturaleza, que vive ajena a su eterno fluir. Moscarda encuentra la paz en la vida desnuda, en la elementalidad y en la muerte civil. En este sentido, Moscarda es una vez más hermano del protagonista de Niebla de Miguel de Unamuno: "Sólo a solas, dice de Augusto Pérez, se sentía él; sólo a solas podía decirse a sí mismo, tal vez para convencerse, ¡Yo soy yo!; ante los demás, metido 
en la muchedumbre atareada y distraída, no se sentía él mismo." Y, como Moscarda, Augusto concluye diciendo que "la única verdad es el hombre fisiológico, el que no habla y no miente..."

Como Pirandello, Unamuno piensa que "la palabra, ese producto social, se ha hecho para mentir", y que "todo lo que es producto social es mentira". Son mentira las relaciones sociales porque, dice Augusto, "no hacemos más que representar cada uno su papel". "El hombre en cuanto habla miente y en cuanto se habla a sí mismo se miente". El mismo pesimismo expresa Pirandello: la palabra hecha para unir en realidad separa. El lenguaje se ha vuelto pura abstracción, no sirve porque las palabras tienen un sentido para uno, un valor "como son dentro de uno", mientras que quien las escucha "las asume inevitablemente con el sentido y el valor que tienen para sí mismo, el sentido y el valor del mundo que tiene adentro". Décadas más tarde, Elías Canetti dirá que no hay mayor ilusión que la del lenguaje como medio de comunicación, y que la deformación del lenguaje conduce al caos de las figuras separadas. Cada hombre posee una fisonomía lingüística que lo diferencia de los demás, pero esta fisonomía se ha vuelto una "máscara acústica" que marca al ser humano, dando la apariencia de una individualidad y una personalidad de hecho inexistentes. "Los hombres se hablan pero no se entienden, y el diálogo entre ellos se ha transformado en un monólogo de paranoicos, un ruido acústico".

Se podría objetar que estos escritores denuncian la incomunicabilidad del lenguaje valiéndose del mismo lenguaje que ponen en duda. El hecho es que tienen fe en el arte y en la poesía, que consideran capaces de "oír", percibir y tener acceso a lo que el ser humano es detrás de las palabras. El escritor, dirá bellamente Canetti, otorga particular importancia a las palabras, a las que destrona para entronizarlas luego con mayor aplomo, con la voluntad de responsabilizarse por todo cuanto 
admita una formulación verbal, y de expiar incluso sus posibles fallas.

A los cincuenta años, Pirandello empieza a escribir para el teatro, y lo que hubiera tenido que ser un breve paréntesis para regresar a su auténtica vocación de narrador lo absorbió por completo. Teatro y narrativa son dos tipos de comunicación diferente; entre escritura y creación escénica, espectáculo, hay una relación de contraste: por un lado la preeminencia de la escritura, y por otro la sumisión del texto a los espejismos transitorios de la escena, un contraste del que Pirandello tiene conciencia. Sin embargo, el paso al teatro le fue fácil porque la teatralidad existía en potencia en su obra narrativa, y no podía más que desembocar lógicamente en el teatro. Pirandello traspasó al teatro una problemática ya redondeada en su obra narrativa, machacando sobre los mismos temas de manera obsesiva y fundiendo la deformación grotesca y la tensión dramática. Su vitalidad visionaria, su genial capacidad de improvisación, su prodigioso dominio del diálogo, le permitieron encarnar sentimientos e ideas en los personajes de su drama.

Antes de llegar a la creación teatral, Pirandello se había interesado en el teatro como lector y como espectador, y había sido un apasionado del teatro de marionetas, que en Sicilia tiene una larga tradición popular. En El difunto Matías Pascal se encuentra una divertida y no menos acertada metáfora de la diferencia entre el teatro clásico y el teatro moderno, que vale la pena referir brevemente. Anselmo Paleari, el dueño de la pensión romana donde Matías Pascal vive bajo el nombre de Adriano Meis, le aconseja ir a ver la Electra de Sófocles, puesta en escena por una compañía de marionetas. A su regreso, Paleari le pregunta qué pasaría si en el momento culminante, cuando Orestes está por vengar la muerte de su padre, se abriera de repente un hoyo en el techo de cartón del teatro. Al ver que Matías no puede responder, le explica: "Es muy fácil, señor Meis, Orestes quedaría muy desconcertado por aquel 
agujero. Todavía sentiría los impulsos de la venganza, querría cumplirlos con ansiosa pasión, pero los ojos se le irían allí, a aquel agujero, por donde penetrarían en la escena toda clase de malos influjos, y se extraviaría. Orestes, en fin, se volvería Hamlet. Toda la diferencia entre la tragedia antigua y la tragedia moderna consiste en eso, créame: en ese agujero en el techo de cartón." Una metáfora que puede aplicarse también al teatro pirandelliano: el demonio del análisis, lo que Cesare Pavese llama la "carcoma del análisis", de la especulación que debilita la voluntad y aleja de la acción.

Dice Vitangelo Moscarda: "A cada palabra que se me decía o mosca que oía volar, me hundía en abismos de reflexiones y consideraciones que excavaban en mí, perforando de arriba a abajo mi espíritu, como una madriguera de ratas, sin que nada se advirtiera afuera". 